\title{
The Belief Stroop: Information Processing and the Relationship between Religious and Paranormal Belief
}

\author{
Krissy Wilson, John S. Finn, and Heike Wilson
}

\begin{abstract}
Belief in the paranormal is a worldwide trend and appears to be on the increase yet researchers consistently fail to find concrete evidence to support the claims. Attempts have been made in recent years to understand the psychological mechanisms that create and maintain such beliefs. The current research continues that field of enquiry with a three-pronged strand that considers 1) a possible biological component to belief 2) the relationship between religious and paranormal belief and 3) the role of individual differences and belief. The following describes two experiments that employ a unique adaptation of the emotional stroop test to investigate the emotional impact of belief, the link between religion and the paranormal and personality measures of fantasy proneness. Results reveal no link between the two belief constructs, mixed evidence for biological bases but clear evidence of a relationship between fantasy proneness and belief.
\end{abstract}

Index Terms-Belief, emotion, paranormal, stroop.

\section{INTRODUCTION}

The current skeptical view warns against the perils of unfounded beliefs; belief in phenomena that contradicts our known scientific understanding. Yet, belief in the paranormal and related phenomena remains a powerful symptom of the human condition. Opinion polls throughout the world indicate that beliefs in extraordinary phenomena appear to be on the increase. A recent poll conducted in the US, for example, shows evidence that approximately $65 \%$ of the population are likely to believe in psychic phenomena such as talking to the dead, telepathy and precognition [1]. Similarly in a poll carried out by The Readers' Digest in the UK shows that approximately $45 \%$ of respondents believed in telepathy and two thirds of those interviewed believed that there was life after death [2]. These are by no means unusual findings, on the contrary, similar results are shown throughout both Western and Eastern cultures.

Despite the seeming ubiquitous nature of beliefs of this kind, skeptics would suggest that continued and scientific exploration of these types of phenomena fail consistently to produce reliable and replicable evidence for support of these claims [3]. Instead skeptical researchers and commentators maintain that the evidence put forward is anecdotal at best, employs faulty methodology and may even be the results of wishful thinking and in some cases outright fraud [4].

In recent years however, a considerable amount of work

Manuscript received September 30, 2013; revised November 29, 2013. This work was supported in part by an internal grant from the Faculty of Arts at Charles Sturt University, Bathurst, New South Wales, Australia. The authors would also like to acknowledge the sponsorship for this research and other works carried out by this research laboratory, from the Australian Skeptics whose support and encouragement is much appreciated.

Krissy Wilson is with the Macquarie University Australia (e-mail: drkrissywilson@yahoo.com). has focused on understanding the mechanisms that create and maintain such beliefs and a host of theoretical positions have been presented to explain belief in these types of phenomena. French and Wilson for example suggest that the role of cognitive biases is crucial, whilst others suggest that individual difference measures may provide clues as to why people maintain these beliefs [5].

Current thinking is that belief is culturally driven. Few however, have suggested that there is a biological, innate component to belief. The principle aim of this study was to investigate the biological bases of belief. The study will focus specifically on the role of emotion in both religious and paranormal belief whilst examining the potential relationship between the two beliefs constructs. The primary method will be to use an adaptation of the Emotional Stroop (ES) test to explore the emotional impact on cognitive processing via Stroop interference using belief related words - The Belief Stroop (BS). This will be the first time that the stroop test has been used to look at the mechanisms supporting the complexities of human belief as a way to distinguish the potential relationship between religious and paranormal belief.

A secondary aim is to explore personality correlates associated with religious and paranormal belief such as fantasy proneness. It is expected that belief related words will interfere with the color naming task for believers and support the hypotheses that belief has a strong emotional component, further that this tendency will correlate with a greater susceptibility to fantasy proneness.

To date the biological bases of belief has focused on personality correlates. However, to date little research has looked at the role of emotional disturbance and belief. An adaptation of the Emotional Stroop would be an effective way to explore this notion. The original Stroop test [6] was initially used to study processes of attention with participants asked to name the color of an item (a word) while attempting to ignore the word itself e.g. the word 'red' might appear in green ink. Typically it takes the respondents longer to name the colors that are incongruent with the item. An adaptation of the original was devised (The Emotional Stroop) to examine psychopathology. A robust finding for example is that patients with anxiety disorders show high Stroop interference for threat related words [7]. To investigate the emotional impact of belief, a further adaptation of the ES is here proposed to use belief related words to measure the emotional response to belief-related information. It is hypothesized that believers (religiosity and paranormal) will take longer to respond in a color-naming task compared to non-believers for belief related words. Although this line of enquiry is in its early stages, the results of this study may lend support to the notion that belief is an innate human property and that we may well be pre-programmed to believe for 
adaptive purposes.

A second strand of enquiry will look at the relationship between paranormal belief and religious belief. Intuitively it would appear that the two constructs work in parallel and that religious belief would correlate with paranormal belief especially for Christian religions such as the Catholic faith which has a supernatural element to its doctrines. However, the reality is that this is not the case with some researchers finding a mixed pattern of results. For example, some have found that the two work in tandem i.e. that if a person has strong religious beliefs they will also believe in certain paranormal phenomena. Others have found the opposite with no relationship between the two. This is a puzzling finding and suggestion has been made that the two are distinct constructs. The Belief Stroop paradigm may prove an effective way of examining the possible relationship between these two beliefs constructs.

A final strand will focus on personality correlates and belief. Could there be a belief personality, for example? Someone who is particularly susceptible to paranormal or religious beliefs? The general pattern of results is fairly mixed but some tentative conclusions can be drawn from the research to date. Researchers have typically looked at factors such as dissociation, fantasy-proneness and suggestibility, and their relationship to various beliefs. Dissociativity describes a tendency to drift in and out of conscious awareness. In extreme cases patients may develop severe schizotypical symptoms and are as a result, unable to function normally. But in most cases, and those that are explored in the laboratory, dissociation is a common occurrence of a brief disconnection from full self-awareness, of time and of external circumstances and has been shown to correlate with belief in the paranormal in a number of studies [8], [9].

A similar pattern emerges when looking at fantasy-proneness. Fantasy proneness, like dissociation, exists on a continuum from mild examples to clinical cases where patients have an inability to distinguish fantasy from reality. They may report vivid childhood memories, show elevated levels of hypnotic suggestibility, and claim to have psychic abilities.

This study focuses on two key questions: the role of emotion in the mechanism of belief, and the relationship between religious and paranormal belief. This study introduces a novel adaptation of the Stroop test to investigate the emotional nature of belief. Furthermore, it supports the notion that religious and paranormal beliefs are separate constructs. To investigate this further data from personality measures were also collected to investigate the role of fantasy proneness and belief.

\section{METHOD}

The study consists of two separate experiments. The rationale for splitting the study into two distinct conditions was to investigate the relationship between paranormal and religious belief as two separate constructs.

\section{A. Experiment 1 - The Belief Stroop (Paranormal Belief) Participants}

One hundred and forty three first year students took part in experiment 1. All students were recruited from Charles Sturt University from the Albury-Wodonga campus, New South Wales. Participants included physiotherapy, occupational therapy, speech pathology and nutrition first year undergraduates. The sample consisted of 24 males and 119 females, age range of $18-49$ years with a mean age of 20.5 years $(S D=5.1)$. Participants received course credit for their participation.

\section{B. Materials/Procedure}

In both experiments all participants were required to complete two phases of the study. These consisted of a tenminute computerized version of the Stroop test and then to complete a small battery of questionnaires. The two phases of the experiment were randomized to control for potential order effects. Therefore, half of the participants completed the questionnaires first whilst the other half completed the computer trial. To further control for order effects, boredom or fatigue, participants were randomly assigned to complete the computer trial first or second.

The initial stage of the study involved the compilation of word lists. 20 words associated with the paranormal were complied for experiment 1 (e.g., "Psychic", "Ghost") and 20 words associated with religious beliefs (e.g. "Priest", "Spiritual") were compiled for experiment 2. An additional selection of 20 neutral words was complied for use as controls for both experiments. An online version of the Stroop test was acquired and an adaptation was designed to utilize paranormal and religious words as the target words and a third list of neutral words. Four different colors were used: red, yellow, blue and green respectively. Each word was displayed on the screen a total of four times during each individual trial and in random order and color. For the computerized phase of the study, after a brief explanation of the procedure each participant sat at the computer screen and words were randomly displayed in no particular order and in different colors. Participants were required to name the color of the words they saw by hitting the appropriate key on the keypad. Four keys were labeled blue, green, red or yellow respectively for this purpose. All participants were given an initial trial of ten randomly chosen words in random colors to ensure they understood the procedure.

Reaction times were collected for religious, paranormal and neutral words.

The second phase of both experiments involved the completion of a battery of questionnaires that included demographic information such as religious denomination, gender and age, followed by a selection of belief questionnaires designed to produce quantitative data on an individual's level of belief in these phenomena. These included the Australian Sheep/Goat Scale (ASGS), the Anomalous Experiences Inventory (AEI) and the Religious Orientation Scale (ROS). Finally, participants completed a personality questionnaire to measure fantasy -proneness (The Creative Experiences Inventory; CEI). Questionnaires were counterbalanced Computer to alleviate the potential for order effects.

Paranormal belief was measured using two scales, The Australian Sheep/Goat Scale and The Anomalous Experiences Inventory. These are self-report scales that require the participant to answer 'true', 'unsure' or 'false' to a 
series of statements, such as 'Hearing about the paranormal or psychic experiences is scary'. The ASGs determines an individual's overall level of belief in paranormal phenomena through an 18-item questionnaire. The AEI assesses both the paranormal beliefs of the individual and any paranormal experiences they have had through a 70 item questionnaire and is made up of the five different subscales of Experience, Belief, Ability, Fear and Drugs, thus the combined use of these two scales gives a good indication of each participant's level of paranormal belief and personal experience of paranormal phenomena.

The ASGS is designed to measure belief in and alleged experience of, the paranormal and related extraordinary phenomena. It consists of 18 items that all relate specifically to the three core concepts of parapsychology: ESP (extrasensory perception), PK (psycho kinesis), and life after death. Example items are "I believe I have personally exerted PK on at least one occasion" and "I believe in life after death". For all items, the response options are "True", "?" (i.e., don't know) and "False" resulting in a score of 2, 1 or zero points per item, respectively. Thus the scale has a theoretical range from zero to 36, with higher scores indicating higher levels of belief in and experience of the paranormal. The ASGS has been widely used and has proven reliability and validity [10].

For experiment 1., after a brief explanation of the procedure each participant was allocated to either the computerized test or completion of the questionnaires. The computerized color-naming test (the Belief Stroop test) required participants to name the color of a word presented on the screen. The words consisted of a list of 20 neutral words (e.g. 'chair', 'window', 'pencil') and a list of paranormal related (emotional) words e.g. 'psychic', 'telepathy', and 'ghost'. Participants had a ten word practice trial followed by the presentation of a further 80 trials with each word from both lists presented in four colors; red, yellow, green or blue. They were presented in random order and color a total of four times each, thus creating 80 trials. Response time in milliseconds was recorded for each of the words presented.

At the end of the computerized part of the study participants then filled out the battery of questionnaires. These were randomized to prevent order effects.

\section{Experiment 2 - The Belief Stroop (Religious Belief) Participants/Procedure}

The second experiment was carried out under similar conditions using the same procedure and apparatus. Participants completed the same battery of questionnaires and the computerized trials. However, for this second experiment the target emotional words were replaced with religious words such as 'Holy', 'Sacrament', and 'Priest'. The neutral words were also changed slightly. It was found in Experiment 1 that the word 'trousers' was considered to be unusual for an Australian sample, this being more common in the UK. Therefore for the second experiment 'trousers' was replaced with 'table'.

Participants for this experiment consisted of a new set of first year undergraduate students from Charles Sturt University and volunteers from the local community who responded to media advertisements for research participation in the newly formed Science of Anomalistic Phenomena
(SOAP) research unit at the Albury campus. In total 139 participants took part ( $n=124$ students; $n=15$ non-students) with 30 males and 109 females with the age range of $18-45$, and a mean age of 23.5 years $(S D=12.4)$. These participants were either first year undergraduates enrolled in physiotherapy, speech therapy and occupational therapy degree courses and gained course credit for their participation or members of the general public described as either 'working' or 'retired'.

\section{RESULTS}

The results focused on three main questions; the role of emotion in belief, the relationship between belief in the paranormal and religious belief and finally, the role of individual difference measures such as fantasy proneness.

For experiment 1 participants were grouped as either believer or non-believer on the basis of a median split from scores on the ASGs. A one way analysis of variance with belief (believer vs non-believer) as grouping variable and response time for the paranormal (emotional) words as dependent variable revealed no significant difference ( $p$ $=0.8$ ). It had been expected that paranormal (emotional) words would have taken longer to process compared to neutral words, however, this hypothesis was not supported, in fact, contrary to the hypothesis response time to the paranormal words was actually quicker compared to the neutral words although these results did not reach statistical significance (see Table I below).

Scores on the personality measures revealed a significant moderate correlation between fantasy proneness and belief in the paranormal as measured by the Australian Sheep/Goat scale $(r=0.51 ; p<0.001)$. It was also found that believers in the paranormal were more likely to score higher on subscales of experience and ability compared to non-believers. These results are in line with precious findings.

For experiment 2 response times for neutral and emotional (religious) words were compared. Once again it had been hypothesized that the response time for the religious words would be significantly longer compared to the non-emotional neutral words for believers compared to non-believers. Participants were once again assigned to either a 'believer' or 'non-believer' grouping variable based upon their religious affiliation. Approximately $48 \%$ of participants reported as being non-religious ('Atheist', 'Agnostic', 'None'), whilst $45 \%$ reported having a religious denominations such as "Catholic", 'Anglican".

TABLE I: MEAN SCORES FOR RESPONSE TIME IN MILLISECONDS FOR PARANORMAL AND RELIGIOUS WORDS FOR BELIEVERS

\begin{tabular}{lll}
\hline & paranormal & religious \\
Mean & 801 & 794 \\
SD & 158.1 & 205 \\
\hline
\end{tabular}

TABLE II: MEAN SCORES FOR RESPONSE TIME IN MILLISECONDS FOR PARANORMAL AND RELIGIOUS WORDS AND NEUTRAL WORDS FOR

\begin{tabular}{lll}
\multicolumn{3}{c}{ NON-BELIEVERS } \\
\hline & paranormal & religious \\
Mean & 809 & 823 \\
SD & 220 & 272 \\
\hline
\end{tabular}

A one-way analysis of variance revealed no significant difference in response time for religious (emotional) words 
between believers and non-believers $(p=0.45)$. Mean scores and SDs for all conditions for both experiments are shown in Table I and Table II.

A similar pattern to experiment 1 emerged for the personality measures with significant small to moderate correlations between fantasy proneness and belief in the paranormal $(r=0.49 ; p<0.001)$.

As hypothesized believers were shown to score significantly higher on fantasy processes compared to nonbelievers for both paranormal and religious beliefs.

\section{DISCUSSION}

The primary aim of the current research was to investigate the role of emotion in paranormal and religious belief. The study used an adaptation of the Emotional Stroop test to reveal the impact of emotion of information processing of belief related words. According to theories of interference using this method it was expected that emotional associations relating to the words would delay response times as has been seen in clinical trials using this method with anxiety related words. However, in this case, there was no difference between the emotionally belief charged words and neutral words in either the paranormal or religious conditions.

This was the first time that an adaptation of the Emotional Stroop test specifically with belief related words had been used to explore the relationship between religious and paranormal belief. Given the inconclusive findings, it is not clear if the Belief Stroop is a reliable paradigm for such lines of investigation.

It is interesting to note however, that it was in fact non-believers who took longer to respond to the emotionally charged target words in both the paranormal and religious conditions. This is most likely due to the familiarity of the content and meaning of these words for believers.

Attempts have been made to provide further evidence to support the role of personality measures in belief in the paranormal and religious belief with fantasy proneness significantly higher for both religious and paranormal believers compared to nonbelievers. Researchers have consistently shown a pattern of personality factors that correlate with belief in the paranormal and clearly fantasy proneness provides robust evidence to support the role of certain measures in susceptibility to belief.

\section{ACKNOWLEDGMENT}

Dr. Krissy Wilson would like to acknowledge the continued financial and collegial support of the Australian
Skeptics who sponsored this research project.

\section{REFERENCES}

[1] B. Karr. (26 February, 2012). Gallup: Paranormal belief since 1990 [Online]. Available: http:/www.csicop.org.

[2] S. Hemelryk, Are you normal? Or psychic? Readers Digest (UK Edition), pp. 84-90, June 2006.

[3] R. Hyman, "A critical historical overview of parapsychology," in P Kurtz (ed), A Skeptics' Handbook of Parapsychology, pp. 93-96, Buffalo, NY: Prometheus, 2003.

[4] J. Randi, Flim Flam, Prometheus Books, NY: Amherst, 1980.

[5] C. C. French and K. Wilson, "Cognitive factors underlying paranormal beliefs and experiences," in S. Della Salla (Ed), Tall Tales: Popular Myths About the Mind and Brain, Oxford: Oxford University Press, 2007.

[6] J. Ridley, "Studies of interference in serial verbal reactions," Journal of Experimental Psychology, vol. 18, no. 6, pp. 643-662, 1935.

[7] J. M. Williams, A. Mathews, and C. Macleod, "The emotional stroop task and psychopathology," Psychological Bulletin, vol. 120, no. 10, pp. 3-24, 1996.

[8] H. Irwin, "Paranormal beliefs and proneness to dissociation," Psychological Reports, vol. 75, pp. 1344-1346, 1994.

[9] U. Wolfradt, "Dissociative experiences, trait anxiety and paranormal beliefs," Personality and Individual Differences, vol. 23, pp. 15-19, 1997.

[10] M. Thalbourne and P. S. Delin, "A new instrument for measuring the sheep-goat variable: its psychometric properties and factor structure," Journal of the Society for Psychical Research, vol. 59, pp. 172-186, 1993.

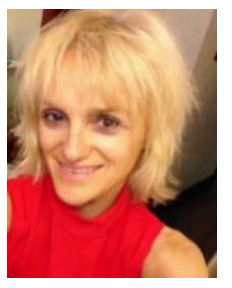

Krissy Wilson is currently working for Macquarie University in Sydney, NSW, Australia. Krissy completed a BSc in Psychology at Birkbeck, University of London and then a PhD at Goldsmiths, University of London in 2006. In 2012 she set up a new research unit called the Science of Anomalistic Phenomena (SOAP). Her main research interests include belief in and experience of the paranormal, the creation of false memories and the role of individual difference measures in belief.

John. S. Finn completed his undergraduate degree in psychology at Goldsmsiths, Univesity of London. His final year thesis was on the subject of the benefits of belief. John is now working in the airline industry as a consultant auditor.

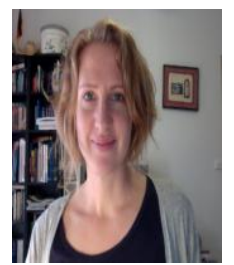

Heike Wilson is currently enrolled in a BSc in Physiotherapy at Charles Sturt University, Albury, New South Wales. For the last two years she has also worked as a research assistant for the Science of Anomalistic Phenomena (SOAP) research unit. 